\title{
Mineração
}

\section{Melhoria da qualidade da água em bacias de decantação localizadas em áreas de extração de areia}

\author{
(Water quality management at floculation basins \\ localized on sand extration)
}

\author{
Cibele Teixeira Paiva \\ Mestranda, CPGEM/UFMG \\ E-mail: cibelepaiva@gmail.com
}

Raul Zanoni Lopes Cançado

Professor Adjunto do Departamento de Engenharia de Minas da UFMG

E-mail: rzanoni@demin.ufmg.br

\section{Resumo}

A produção de areia para uso em construção civil possui uma demanda muito alta no Estado de Minas Gerais. $\mathrm{O}$ mercado produtor tem procurado alternativas para o fornecimento desse bem mineral por outros processos que não seja a lavra em aluviões de rios, que se encontra em franca exaustão e gera um enorme passivo ambiental, restando, como alternativa, a lavra de areia diretamente nas barragens de usinas hidrelétricas. Esse processo gera um efluente que é lançado diretamente no curso d'água, provocando um sensível aumento na turbidez. Esse trabalho propõe medidas que visam a diminuir a turbidez do efluente através do uso de reagentes coagulantes. Foram testadas diversas substâncias coagulantes, concluindose pela utilização do sulfato de alumínio.

Palavras-chave: Qualidade das águas, turbidez, produção de areia.

\begin{abstract}
The consumption of sand for building has been highly increased in the last years in Minas Gerais state, southeastern Brazil. The producers are in the search for alternatives to grow the production and reduce the environmental impacts, because the main source of industrial sand in the state is the rivers beds. This work proposes some measures concerning the reduction of the high turbidity in the stream waters affected by the mining activity. The treatment in the sedimentation basins in the area of sand production is proposed using aluminum sulphate, ferric chloride, chalk and a commercial cationic polymer as flocculants substances.
\end{abstract}

Keywords: Water quality, turbidity, sand production. 


\section{Introdução}

A produção de bens minerais para uso in natura na construção civil é uma importante atividade minerária, pelo grande volume produzido e pela ampla distribuição geográfica dos centros produtores. Entre esses recursos, destaca-se a areia, pelas suas características intrínsecas: mineração em planícies aluvionares ou no próprio leito fluvial, intervenção voluntário-involuntária em áreas de proteção ambiental, o que acarreta impactos por vezes de alto poder degradante.

O mercado produtor tem procurado alternativas para o fornecimento de areia por outros processos que não os tradicionais, mas, até o momento, essas alternativas têm se mostrado com custos mais elevados que o processo de extração de areia natural.

Uma alternativa mais viável do ponto de vista ambiental é a extração de areia diretamente dos leitos fluviais por dragagem embarcada, pois não acarreta impactos de grande magnitude nas planícies aluvionares, assim como não elimina vastos trechos de matas ciliares.

No Triângulo Mineiro, essa forma de extração de areia se impõe como a única alternativa viável, por dois motivos. Primeiro pela quase inexistência de depósitos aluvionares naturais, dado o profundo encaixamento dos principais rios. Segundo, pelas imensas áreas de inundação das barragens das usinas hidrelétricas instaladas na região, o que resultou na quase extinção de trechos naturais dos rios, interferindo drasticamente na dinâmica fluvial. Por esses motivos, atualmente a forma mais viável de extração de areia, em escala industrial, na região do Triângulo Mineiro, tem sido nos lagos das usinas hidrelétricas. Nesse aspecto, a dragagem de areia, além de representar uma atividade econômica importante em uma região cuja indústria da construção civil se encontra em expansão, ainda acarreta um impacto positivo para a geração de energia elétrica, que é justamente o desassoreamento das barragens.
Em contrapartida, o mais relevante impacto negativo dessa atividade é o aumento da turbidez nas barragens, devido ao lançamento direto dos efluentes gerados no processo, isto é, sem nenhum tratamento prévio. Nas proximidades dos denominados "portos de areia", o que se verifica é a formação de um halo de turbidez que, dependendo da época do ano, gera um impacto visual de grande extensão, em especial devido ao fato de que, nas barragens, praticamente não existem correntezas que permitam a sua dispersão. Acrescenta-se a isto mais um fato: a elevada turbidez pode acarretar impactos ainda não mensurados nos ecossistemas locais; que por sua vez já foram alterados em suas condições originais pela implantação das barragens.

Esse trabalho visa, portanto, a procurar medidas que eliminem, ou, pelo menos, atenuem a turbidez da água resultante deste processo. Para a realização desse estudo, foi selecionada uma empresa de extração de areia cujas instalações se situam às margens do lago da Usina Hidrelétrica - UHE Miranda, limite dos municípios de Uberlândia e Nova Ponte, região do Triângulo Mineiro. No local, foram realizados testes com substâncias coagulantes que permitiram a clarificação da água retornante do processo (Paiva, 2004).

A pesquisa em questão, interessando exclusivamente a extração de areia para construção civil e de acordo com os parâmetros estabelecidos pela Resolução CONAMA 357, é pioneira.

\section{Material e métodos 2.1 Descrição do processo}

A extração de areia nas barragens das usinas hidrelétricas, conforme mostrado no perfil esquemático da Figura 1, é feita por meio de dragas de sucção acopladas em barcaças, o que permite atingir uma considerável profundidade. As barcaças, uma vez cheias, dirigem-se aos portos de areia, onde são despejadas sob a forma de polpa, lavadas e algumas vezes classificadas. Todo o processo requer a utilização de água captada dire- tamente das barragens durante a dragagem da areia, que, por sua vez, retorna a ela com a turbidez bastante elevada, pois o sistema de lavagem, com drenos e bacias de decantação geralmente não rigorosamente dimensionadas, não permite a sedimentação da matéria fina em suspensão. Ressalte-se que essas bacias, denominadas "bacias de decantação", na verdade, não chegam ainda a sê-las, pois a água que aporta a elas sofre apenas sedimentação por ação da gravidade.

\subsection{Metodologia}

A extração de areia no local onde foram realizados os trabalhos é feita através do processo descrito. $\mathrm{Na}$ empresa, existem atualmente quatro barcos com dragas de sucção acopladas, que chegam ao porto e descarregam a polpa (mistura de água e areia) através de uma tubulação, formando grandes cones de deposição no local denominado regionalmente por "paiol".

A partir desse momento a polpa perde densidade (aproximadamente 1,6g/ $\mathrm{cm}^{3}$ ), gerando um efluente com turbidez bastante elevada e que, na verdade, trata-se essencialmente de água e partículas de granulometria areia média a fina. Essa água é direcionada por gravidade para a $1^{a}$ bacia de decantação, que, em realidade, nada mais é do que um sistema de barramento sem capacidade medida, com seis vertedouros dispostos em série e com uma inclinação em torno de $3 \%$. Os vertedouros conduzem a água drenada para uma canaleta, que a direciona para uma $2^{\mathrm{a}}$ bacia de decantação, com capacidade em torno de 100.000 litros. O processo é mostrado na planta esquemática da Figura 2.

$\mathrm{Na} 2^{\mathrm{a}}$ bacia, a água se estaciona e o material em suspensão, com o passar do tempo, é sedimentado, permitindo apenas uma clarificação parcial antes que ela retorne à margem do lago por meio de tubulação. A clarificação por esse processo é bastante dificultada, especialmente na estação seca (meses de maio a setembro), quando a produção aumenta 


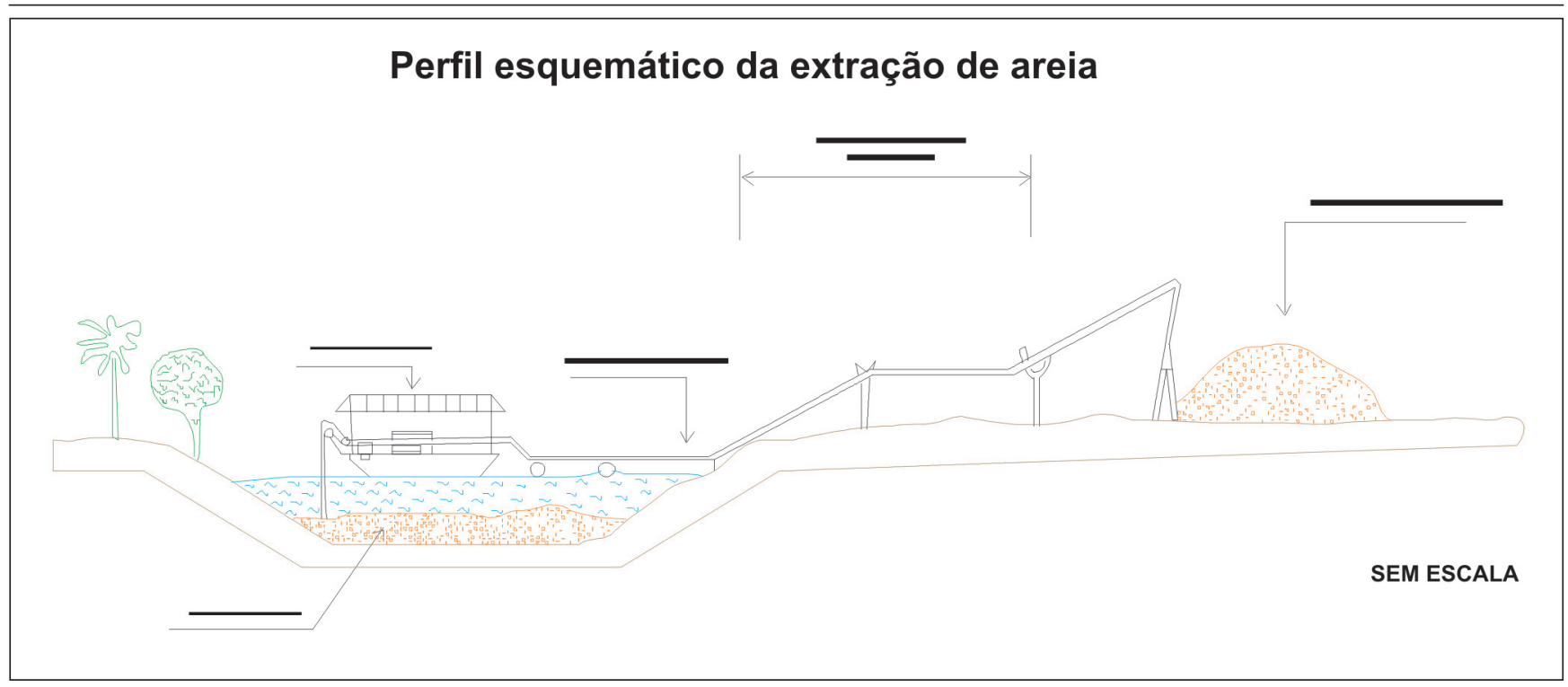

Figura 1 - Perfil esquemático da extração de areia em leitos de rios.

e o tempo de sedimentação diminui em conseqüência do aporte de um número maior de barcaças ao porto. Esse é hoje o maior impacto de maior potencial observado pelo órgão ambiental fiscalizador.

Para realização desse trabalho, foram considerados os valores estabelecidos pela legislação federal através da Resolução CONAMA No.357, de 17/03/ 2005, que estabelece condições e padrões de lançamento de efluentes, além de classificar os corpos-de-água. Para tal foram considerados os limites estabelecidos para as coleções de água de Classes 3 e 4, conforme Tabela 1, uma vez que, para os parâmetros considerados nesse trabalho, não são estabelecidos limites quando se trata de lançamento de efluentes, exceto para $\mathrm{pH}$.

O trabalho foi realizado em três etapas, sendo cada uma delas compreendida por trabalhos de campo seguidos por ensaios e testes laboratoriais. A $1^{\mathrm{a}}$ etapa foi realizada na estação chuvosa, a $2^{\mathrm{a}}$ na estação seca; a $3^{\mathrm{a}}$ e última etapa compreendeu os ensaios com reagentes in loco com posterior coleta de amostras e ensaios laboratoriais. Todas as determinações de coleta e laboratoriais foram executadas com base nos procedimentos descritos no Standard Methods for Examination of Water and Waste Water (APHA, 2005).

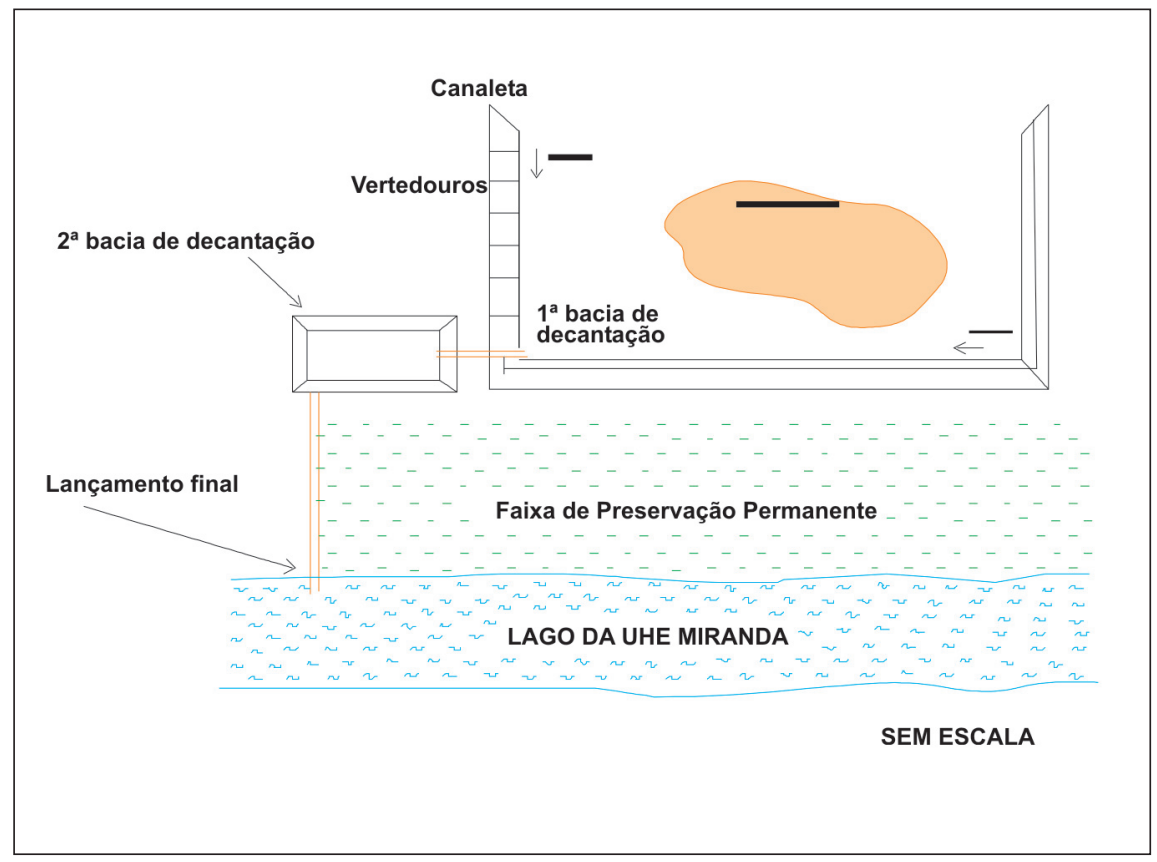

Figura 2 - Planta esquemática.

\section{$1^{\mathrm{a}}$ e $2^{\mathrm{a}}$ etapas}

Nessas etapas, as amostras de água foram coletadas nos seguintes pontos: lago da UHE em dois locais: a montante e a jusante do lançamento; $1^{\text {a }}$ bacia de decantação; canaleta; $2^{\mathrm{a}}$ bacia de decantação e lançamento final.

Posteriormente foram realizados os ensaios laboratoriais:
- Caracterização das amostras. Parâmetros analisados: pH, turbidez e sólidos em suspensão, demanda biológica de oxigênio (DBO), demanda química de oxigênio (DQO), demanda de oxigênio (OD), alumínio total e ferro total.

- Testes de sedimentabilidade.

- Ensaios com coagulantes através do teste de jarros. 
Melhoria da qualidade da água em bacias de decantação localizadas em áreas de extração de areia

Tabela 1 - Limites estabelecidos pela Resolução CONAMA 357 para lançamento de efluentes em corpos de água de Classe 3 e 4 .

\begin{tabular}{l|c|c|c}
\hline \multicolumn{1}{c|}{ Parâmetro } & Classe 3 & Classe 4 & $\begin{array}{c}\text { Lançamento de } \\
\text { efluentes }\end{array}$ \\
\hline Alumínio Dissolvido & $0,2 \mathrm{mg} / \mathrm{L} \mathrm{Al}$ & $1,5 \mathrm{mg} / \mathrm{L} \mathrm{Al}$ & Não estabelecido \\
\hline Oxigênio Dissolvido - OD & Não inferior a $4,0 \mathrm{mg} / \mathrm{L} \mathrm{O}_{2}$ & Não inferior a $2,0 \mathrm{mg} / \mathrm{L} \mathrm{O}_{2}$ & Não estabelecido \\
\hline $\begin{array}{l}\text { Demanda Bioquímica de } \\
\text { Oxigênio - DBO }\end{array}$ & Até $10 \mathrm{mg} / \mathrm{L} \mathrm{O}_{2}$ & Até $10 \mathrm{mg} / \mathrm{L} \mathrm{O}_{2}$ & Não estabelecido \\
\hline $\begin{array}{l}\text { Demanda Química de } \\
\text { Oxigênio - DQO }\end{array}$ & Não estabelecido & Não estabelecido & Não estabelecido \\
\hline Turbidez & Até $100 \mathrm{UNT}$ & Não estabelecido & Não estabelecido \\
\hline pH & Entre 6 a 9 & Entre 6 a 9 & Entre 5 a 9 \\
\hline
\end{tabular}

\section{$3^{\mathrm{a}}$ etapa}

Essa etapa compreendeu os testes in loco, com adição de reagentes na canaleta, e coleta de amostras na $2^{\text {a }}$ bacia de decantação e no lançamento final, após a injeção do coagulante.

Posteriormente foi feita a caracterização das amostras, com a análise dos parâmetros: alumínio total, $\mathrm{pH}, \mathrm{OD}$ e DBO.

\section{Coagulantes utilizados}

Foram utilizados quatro reagentes/ coagulantes durante os ensaios laboratoriais. Esses ensaios foram feitos através do teste de jarros, onde foram testadas dosagens diferentes em tempos de agitação e decantação diferentes. Foi controlado o $\mathrm{pH}$ para que se mantivesse dentro dos parâmetros aceitáveis e tomadas medidas de turbidez e sólidos em suspensão em cada intervalo de tempo de decantação. O objetivo principal foi de se obter uma clarificação da água dentro dos limites de turbidez desejados, com dosagens de coagulantes e tempo de decantação cada vez menores.

Os coagulantes utilizados foram:

1. Sulfato de alumínio $\left(\left(\mathrm{Al}_{2} \mathrm{SO}_{4}\right)_{3} 18 \mathrm{H}_{2} \mathrm{O}\right.$ a $2 \%$ ).

2. Cloreto férrico $\left(\mathrm{FeCl}_{3}\right)$.
3. Leite de cal $\left(\mathrm{Ca}(\mathrm{OH})_{2}\right.$ a $0,5 \%$.

4. Polímero catiônico G997 (fabricante: Adesol Produtos Químicos Ltda).

As dosagens usadas para cada um variaram entre $7,5 \mathrm{mg} / \mathrm{L}$ a $40 \mathrm{mg} / \mathrm{l}$, com tempos de agitação entre 1 a 30 minutos. A rotação variou entre 20 a $105 \mathrm{rpm}$. O tempo de decantação variou entre 10 a 40 minutos.

\section{Testes com reagentes em campo}

Após os ensaios em laboratório, concluiu-se que os testes em campo da $3^{\mathrm{a}}$ etapa seriam feitos com sulfato de alumínio ( $\left(\mathrm{Al}_{2} \mathrm{SO}_{4}\right)_{3} 18 \mathrm{H}_{2} \mathrm{O}$ a $2 \%$ ) nas dosagens $10 \mathrm{mg} / \mathrm{L} \mathrm{e} 7,5 \mathrm{mg} / \mathrm{L}$. Os reagentes foram injetados na canaleta, após foi feita a agitação manual com pás, na $2^{\mathrm{a}}$ bacia de decantação, por 40 minutos. $\mathrm{O}$ período de decantação foi de 2 horas e 30 minutos.

\section{Resultados e discussões}

Na Tabela 2, estão apresentados os valores dos ensaios laboratoriais propostos para a $1^{\text {a }}$ etapa, na Tabela 3 , os valores determinados nos ensaios da $3^{\mathrm{a}}$ etapa e, na Tabela 4 , os valores da $3^{\text {a }}$ etapa.
As amostras coletadas na $2^{\mathrm{a}}$ bacia de decantação e no lançamento final após a injeção do coagulante na canaleta mostraram que as duas dosagens do sulfato de alumínio atenderam aos limites de turbidez estabelecidos pela legislação. Apenas para a dosagem de 7,5 mg/L de sulfato de alumínio o valor da turbidez se aproxima bastante do limite máximo.

Com relação aos outros parâmetros analisados, todos os resultados estavam dentro dos limites legais.

O material decantado nas bacias é constituído em sua maioria por fragmentos de quartzo, por isto poderia ser feito um estudo do emprego deste. Assim, um impacto futuro, que seria o problema da deposição desse rejeito, poderia ser solucionado.

No caso de rios com valores muito discrepantes de algum parâmetro físicoquímico relevante, nesse caso, será necessária a modificação das dosagens ou o uso de outro reagente para a eliminação da turbidez. Em águas com pH mais ácido e bacias hidrográficas muito poluídas, o sulfato de alumínio poderá não ser o mais adequado.

a) Geralmente, nesse tipo de lavra, não se tem um controle rigoroso da quantidade de areia extraída, nem do volume de polpa gerado. $\mathrm{O}$ cálculo é feito a 
Cibele Teixeira Paiva et al.

Tabela 2 - Resultados dos ensaios laboratoriais da $1^{a}$ etapa.

\begin{tabular}{|c|c|c|c|c|c|c|c|c|}
\hline \multirow[b]{2}{*}{ Local } & \multirow[b]{2}{*}{$\begin{array}{l}\text { Série de } \\
\text { ensaios }\end{array}$} & \multicolumn{4}{|c|}{ Reagentes / dosagens (mg/l) } & \multirow{2}{*}{$\begin{array}{c}\text { Tempo de } \\
\text { agitação }(\mathrm{min}) \\
\text { rotação }(\mathrm{rpm})\end{array}$} & \multirow[b]{2}{*}{$\begin{array}{c}\text { Turbidez } \\
\text { (UNT) }\end{array}$} & \multirow{2}{*}{$\begin{array}{c}\text { Sólidos em } \\
\text { suspensão } \\
\text { (mg/L) (após } \\
30 \text { min de } \\
\text { decantação) }\end{array}$} \\
\hline & & Cal (mg/L) & $\begin{array}{c}\text { Sulfato de } \\
\text { alumínio (mg/L) }\end{array}$ & $\begin{array}{l}\text { Polímero } \\
\text { aniônico }\end{array}$ & $\begin{array}{l}\text { Cloreto férrico } \\
\text { (mg/L) }\end{array}$ & & & \\
\hline \multirow{22}{*}{$\frac{\frac{\pi}{0}}{\frac{\pi}{\pi}}$} & 1 & & 5 (até pH 7,07) & & & $10 / 40 \mathrm{rpm}$ & 1050 & \\
\hline & 2 & & 10 (até pH 6,88) & & & $10 / 40 \mathrm{rpm}$ & 930 & \\
\hline & 3 & & 20 (até pH 6,54) & & & $10 / 40$ rpm & 80,87 & \\
\hline & 4 & & 30 (até pH 6,04) & & & $10 / 40$ rpm & 14,53 & 11,2 \\
\hline & 5 & & 40 (até pH 5,69) & & & $10 / 40 \mathrm{rpm}$ & 7,98 & 7,6 \\
\hline & 6 & & 25 (até pH 6,71) & & & $10 / 40 \mathrm{rpm}$ & 9,24 & 5,71 \\
\hline & 7 & & 25 (até pH 6,71) & & & $5 / 40 \mathrm{rpm}$ & 15,3 & 8 \\
\hline & 8 & & 25 (até pH 6,71) & & & $3 / 40 \mathrm{rpm}$ & 22,93 & 9,5 \\
\hline & 9 & & 30 (até pH 6,04) & & & $3 / 40 \mathrm{rpm}$ & 18,7 & \\
\hline & 10 & & 25 (até pH 6,71) & $0,20 \mathrm{ml} / \mathrm{L}$ & & $3 / 40 \mathrm{rpm}$ & 50 & \\
\hline & 11 & & 25 (até pH 6,71) & $0,50 \mathrm{ml} / \mathrm{L}$ & & $3 / 40 \mathrm{rpm}$ & 35 & \\
\hline & 12 & & 25 (até pH 6,71) & $1,00 \mathrm{ml} / \mathrm{L}$ & & $3 / 40 \mathrm{rpm}$ & 34 & \\
\hline & 13 & & 25 (até pH 6,71) & $0,50 \mathrm{ml} / \mathrm{L}$ & & $3 / 40 \mathrm{rpm}$ & 20 & \\
\hline & 14 & & 25 (até $\mathrm{pH} 6,71$ ) & $0,50 \mathrm{ml} / \mathrm{L}$ & & $\begin{array}{c}2 / 40 \mathrm{rpm}+15 \\
/ 40 \mathrm{rpm}\end{array}$ & 5 & \\
\hline & 15 & & 25 (até $\mathrm{pH} 6,71$ ) & & & $\begin{array}{c}1 / 105 \mathrm{rpm}+ \\
15 / 40 \mathrm{rpm} \\
\end{array}$ & 1 & \\
\hline & 16 & $30($ até $\mathrm{pH} 10,07)$ & 75 (até $\mathrm{pH} 7,42$ ) & & & $10 / 40$ rpm & 4,98 & \\
\hline & 17 & 30 (até pH 10,07) & 87,5 (até pH 7,21) & & & $10 / 40 \mathrm{rpm}$ & 3,3 & \\
\hline & 18 & 30 (até pH 10,07) & 100 (até pH 6,99) & & & $10 / 40$ rpm & 5,41 & 4,4 \\
\hline & 19 & & & & 5 (até pH 7,41) & $10 / 40$ rpm & 590,67 & \\
\hline & 20 & & & & 10 (até pH 6,93) & $10 / 40$ rpm & 18,9 & \\
\hline & 21 & & & & 12,5 (até $\mathrm{pH} 6,25$ ) & $10 / 40$ rpm & 20,53 & 10 \\
\hline & 22 & & & & 15 (até pH 5,22) & $10 / 40$ rpm & 7,73 & \\
\hline \multirow{13}{*}{ 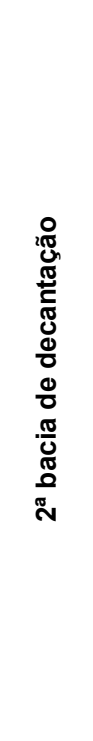 } & 23 & & 5 (até pH 7,02) & & & $10 / 40$ rpm & 1076,67 & \\
\hline & 24 & & 10 (até pH 6,88) & & & $10 / 40$ rpm & 834,33 & \\
\hline & 25 & & 20 (até pH 6,55) & & & $10 / 40$ rpm & 31 & \\
\hline & 26 & & 30 (até pH 5,58) & & & $10 / 40$ rpm & 12,9 & \\
\hline & 27 & & 40 (até pH 4,80) & & & $10 / 40 \mathrm{rpm}$ & 7,73 & \\
\hline & 28 & & 25 (até pH 6,15) & & & $10 / 40$ rpm & 9,02 & \\
\hline & 29 & & 25 (até pH 6,15) & & & $5 / 40 \mathrm{rpm}$ & 16,88 & \\
\hline & 30 & & 25 (até pH 6,15) & & & $3 / 40 \mathrm{rpm}$ & 22,1 & \\
\hline & 31 & & 25 (até pH 6,71) & & & $\begin{array}{c}1 / 105 \mathrm{rpm}+ \\
15 / 40 \mathrm{rpm} \\
\end{array}$ & 2,6 & 1,5 \\
\hline & 32 & 20 (até pH 10,07) & 30 (até pH 7,62) & & & $10 / 40$ rpm & 194,67 & \\
\hline & 33 & 20 (até pH 10,07) & 40 (até $\mathrm{pH} 7,04)$ & & & $10 / 40$ rpm & 26,47 & \\
\hline & 34 & & & & 10 (até pH 6,66) & $10 / 40$ rpm & 7,8 & \\
\hline & 35 & & & & 12,5 (até pH 5,64) & $10 / 40 \mathrm{rpm}$ & 6,46 & $<0,05$ \\
\hline
\end{tabular}


Melhoria da qualidade da água em bacias de decantação localizadas em áreas de extração de areia

Tabela 3 - Resultados dos ensaios laboratoriais da $2^{\mathrm{a}}$ etapa.

\begin{tabular}{|c|c|c|c|c|c|c|c|}
\hline \multirow{2}{*}{ Local } & \multirow{2}{*}{$\begin{array}{l}\text { Série de } \\
\text { ensaios }\end{array}$} & \multicolumn{4}{|c|}{ Reagentes / dosagens (mg/l) } & \multirow{2}{*}{$\begin{array}{c}\text { Tempo de } \\
\text { agitação }(\mathrm{min}) / \\
\text { rotação }(\mathrm{rpm})\end{array}$} & \multirow{2}{*}{$\begin{array}{c}\text { Turbidez (UNT) } \\
\text { / Tempo de } \\
\text { decantação }\end{array}$} \\
\hline & & Cal (mg/L) & $\begin{array}{c}\text { Sulfato de } \\
\text { alumínio }(\mathrm{mg} / \mathrm{L})\end{array}$ & $\begin{array}{l}\text { Polímero } \\
\text { aniônico }\end{array}$ & $\begin{array}{c}\text { Cloreto férrico } \\
\text { (mg/L) }\end{array}$ & & \\
\hline \multirow{9}{*}{$\frac{\frac{\pi}{0}}{\frac{0}{\pi}}$} & 1 & & 15 (até pH 6,25) & & & $\begin{array}{c}1 / 105 \mathrm{rpm}+ \\
15 / 40 \mathrm{rpm}\end{array}$ & $\begin{array}{c}15,93 \text { UNT / } \\
30 \mathrm{~min}\end{array}$ \\
\hline & 2 & & 10 (até $\mathrm{pH} 6,25)$ & & & $\begin{array}{c}1 / 105 \mathrm{rpm}+ \\
15 / 40 \mathrm{rpm}\end{array}$ & $\begin{array}{l}\text { 16,2 UNT / } \\
30 \mathrm{~min}\end{array}$ \\
\hline & 3 & & 5 (até pH 6,18) & & & $\begin{array}{c}1 / 105 \mathrm{rpm}+ \\
15 / 40 \mathrm{rpm}+ \\
10 / 20 \mathrm{rpm}\end{array}$ & $\begin{array}{c}214,67 \text { UNT / } \\
30 \mathrm{~min}\end{array}$ \\
\hline & 4 & & 5 (até pH 6,10) & & & $\begin{array}{c}1 / 105 \mathrm{rpm}+ \\
15 / 40 \mathrm{rpm}+ \\
10 / 20 \mathrm{rpm}\end{array}$ & $\begin{array}{c}198,7 \text { UNT / } \\
120 \mathrm{~min}\end{array}$ \\
\hline & 5 & & 7,5 (até pH 6,10) & & & $\begin{array}{c}1 / 105 \mathrm{rpm}+ \\
15 / 40 \mathrm{rpm}\end{array}$ & $\begin{array}{c}98,12 \text { UNT / } \\
120 \mathrm{~min}\end{array}$ \\
\hline & 6 & 12,5 & 45 & & & $\begin{array}{c}1 / 105 \mathrm{rpm}+ \\
15 / 40 \mathrm{rpm}\end{array}$ & $\begin{array}{c}20 \text { UNT / } \\
30 \mathrm{~min} \\
\end{array}$ \\
\hline & 7 & 12,5 & 35 & & & $\begin{array}{c}1 / 105 \mathrm{rpm}+ \\
15 / 40 \mathrm{rpm}\end{array}$ & $\begin{array}{c}4,53 \text { UNT / } \\
30 \mathrm{~min}\end{array}$ \\
\hline & 8 & & & & 5 (até pH 6,50) & $\begin{array}{c}1 / 105 \mathrm{rpm}+ \\
15 / 40 \mathrm{rpm}\end{array}$ & $\begin{array}{l}\text { 161,33 UNT / } \\
30 \mathrm{~min}\end{array}$ \\
\hline & 9 & & & & 15 (até pH 6,07) & $\begin{array}{c}1 / 105 \mathrm{rpm}+ \\
15 / 40 \mathrm{rpm}+ \\
10 / 20 \mathrm{rpm}\end{array}$ & $\begin{array}{l}48,33 \text { UNT / } \\
20 \mathrm{~min}\end{array}$ \\
\hline \multirow{8}{*}{ 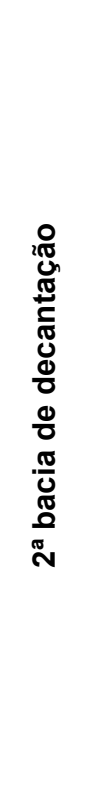 } & 10 & & 5 (até pH 6,60) & & & $\begin{array}{c}1 / 105 \mathrm{rpm}+ \\
15 / 40 \mathrm{rpm}\end{array}$ & $\begin{array}{l}171 \text { UNT / } \\
30 \mathrm{~min}\end{array}$ \\
\hline & 11 & & 10 (até $\mathrm{pH} 6,58)$ & & & $\begin{array}{c}1 / 105 \mathrm{rpm}+ \\
15 / 40 \mathrm{rpm}\end{array}$ & $\begin{array}{l}16 \text { UNT / } \\
30 \mathrm{~min}\end{array}$ \\
\hline & 12 & & 15 (até pH 6,35) & & & $\begin{array}{c}1 / 105 \mathrm{rpm}+ \\
15 / 40 \mathrm{rpm}\end{array}$ & $\begin{array}{c}8,87 \text { UNT / } \\
30 \mathrm{~min}\end{array}$ \\
\hline & 13 & & 20 (até pH 5,99) & & & $\begin{array}{c}1 / 105 \mathrm{rpm}+ \\
15 / 40 \mathrm{rpm}\end{array}$ & $\begin{array}{l}22,20 \text { UNT / } \\
30 \mathrm{~min}\end{array}$ \\
\hline & 14 & 12,5 (até pH 10,11) & 35 (até $\mathrm{pH} 7,40)$ & & & $\begin{array}{c}1 / 105 \mathrm{rpm}+ \\
15 / 40 \mathrm{rpm}\end{array}$ & $\begin{array}{c}4,80 \text { UNT / } \\
30 \mathrm{~min}\end{array}$ \\
\hline & 15 & $\begin{array}{c}18,75 \text { (até } \mathrm{pH} \\
10,19)\end{array}$ & 50 (até $\mathrm{pH} 7,04)$ & & & $\begin{array}{c}1 / 105 \mathrm{rpm}+ \\
15 / 40 \mathrm{rpm}\end{array}$ & $\begin{array}{c}2,42 \text { UNT / } \\
30 \mathrm{~min}\end{array}$ \\
\hline & 16 & & & & 5 (até pH 6,10) & $\begin{array}{c}1 / 105 \mathrm{rpm}+ \\
15 / 40 \mathrm{rpm}\end{array}$ & $\begin{array}{l}182 \text { UNT / } \\
30 \mathrm{~min}\end{array}$ \\
\hline & 17 & & & & 10 (até pH 5,9) & $\begin{array}{c}1 / 105 \mathrm{rpm}+ \\
15 / 40 \mathrm{rpm}\end{array}$ & $\begin{array}{l}23 \text { UNT / } \\
30 \mathrm{~min}\end{array}$ \\
\hline
\end{tabular}


Cibele Teixeira Paiva et al.

Tabela 4 - Resultados dos ensaios laboratoriais da $3^{a}$ etapa.

\begin{tabular}{|c|c|c|c|c|c|c|c|c|c|c|}
\hline \multirow[b]{2}{*}{ Local } & \multirow{2}{*}{$\begin{array}{l}\text { Série de } \\
\text { ensaios }\end{array}$} & Reagente & \multirow[b]{2}{*}{$\begin{array}{c}\text { Tempo de } \\
\text { agitação }\end{array}$} & \multirow[b]{2}{*}{$\begin{array}{c}\text { Tempo de } \\
\text { decantação }\end{array}$} & \multirow[b]{2}{*}{$\begin{array}{c}\text { Turbidez } \\
\text { (UNT) }\end{array}$} & \multirow{2}{*}{$\begin{array}{c}\text { Sólidos em } \\
\text { suspensão } \\
\text { (mg/L) }\end{array}$} & \multirow{2}{*}{$\begin{array}{c}\text { Alumínio } \\
\text { total } \\
\text { (mg/L) }\end{array}$} & \multirow[b]{2}{*}{$\mathrm{pH}$} & \multirow[b]{2}{*}{ OD } & \multirow[b]{2}{*}{ DBO } \\
\hline & & $\begin{array}{l}\text { Sulfato de } \\
\text { alumínio } \\
\text { (mg/L) }\end{array}$ & & & & & & & & \\
\hline \multirow{2}{*}{ 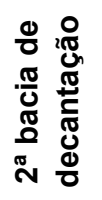 } & 1 & $7,50 \mathrm{mg} / \mathrm{L}$ & $40 \mathrm{~min}$ & $2 \mathrm{~h}: 30 \mathrm{~min}$ & 91 & 80 & $<0,10$ & 6,25 & & \\
\hline & 2 & $10,00 \mathrm{mg} / \mathrm{L}$ & $41 \mathrm{~min}$ & $2 \mathrm{~h}: 30 \mathrm{~min}$ & 48 & 53 & $<0,10$ & 6,6 & & \\
\hline \multirow{2}{*}{ 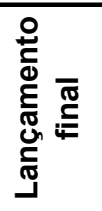 } & 3 & $7,50 \mathrm{mg} / \mathrm{L}$ & $42 \mathrm{~min}$ & $2 \mathrm{~h}: 30 \mathrm{~min}$ & 68 & 51 & $<0,10$ & 6,53 & 7,98 & 3,01 \\
\hline & 4 & $10,00 \mathrm{mg} / \mathrm{L}$ & $43 \mathrm{~min}$ & $2 \mathrm{~h}: 30 \mathrm{~min}$ & 37 & 21 & $<0,10$ & 6,43 & 8,55 & 2,88 \\
\hline
\end{tabular}

partir da capacidade aproximada de cada barco; portanto, deve-se trabalhar com uma dosagem maior que permita que os resultados finais não se aproximem muito dos limites de tolerância.

Durante os trabalhos de campo na região, foi observado, que na maioria das áreas de extração de areia, as condições de lavra não estão adequadas ao processo. Normalmente o que se verifica são bacias de pequeno porte ou a até inexistência destas. Mas a maioria das empresas é de pequeno porte e o intervalo de tempo entre a chegada de um barco e outro é grande o suficiente para a decantação com a adição do reagente. Portanto, na maioria das vezes, a adequação deverá ser em termos de dimensões das bacias.

\section{Conclusões}

A partir dos resultados obtidos nos testes, foi possível concluir o que se segue.
O sulfato de alumínio, na dosagem ótima de $10 \mathrm{mg} / \mathrm{L}\left[\left(\mathrm{Al}_{2}\left(\mathrm{SO}_{4}\right)_{3} 18 \mathrm{H}_{2} \mathrm{O}\right.\right.$ a $\left.2 \%\right]$, é o reagente mais adequado para o caso estudado, por suas características próprias:

a)Fácil manuseio: nesse tipo de lavra, a mão-de-obra não é especializada e, em alguns casos, não se dispõe nem mesmo de energia elétrica.

b) Preço acessível: o produto não é de alto valor agregado, portanto o baixo preço do reagente não irá onerar em muito o preço final do $\mathrm{m}^{3}$ de areia.

\section{Agradecimentos}

Os autores agradecem ao CPGEM-UFMG, à empresa Areia Menezes Ltda. de Uberlândia-MG, pela utilização de suas instalações, ao Laboratório SANEAR Ltda. e aos professores Antonio W. Romano (IGC-UFMG) e Roberto Galery (DEMINEEUFMG).

\section{Referências bibliográficas}

CONSELHO NACIONAL DE MEIO AMBIENTE - CONAMA. Resolução nº 357 de 17 de março de 2005.

PAIVA, C.T. Melhoria da qualidade da água em bacias de decantação localizadas em área de extração de areia. Belo Horizonte: CPGEM-UFMG, 2004. 90p. (Dissertação de Mestrado).

APHA. Standard methods for the examination of water and wastewater. 21 th edition. APHA, AWWA, WEF, 2005.

Artigo recebido em 14/09/2006 e aprovado em 05/05/2008. 